
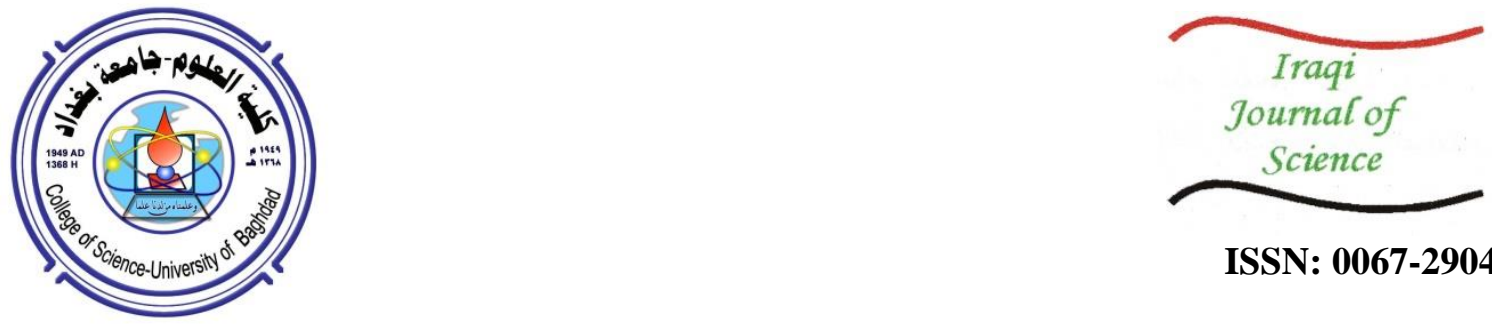

ISSN: 0067-2904

\title{
Synthesis, Characterization, and Antimicrobial Potentials of Some Flavonoid-Metal Complexes from Chromolaena Odorata
}

\author{
Oluwaseyi M. Bamigboye $^{1^{*}}$, Ikechukwu P. Ejidike ${ }^{2}$, Misitura Lawal ${ }^{3}$ \\ ${ }^{1}$ Department of Industrial Chemistry, Faculty of Physical Sciences, University of Ilorin, P.M.B. 1515, Ilorin, \\ Kwara State, Nigeria. \\ ${ }^{2}$ Department of Chemical Sciences, Faculty of Science and Science Education, Anchor University, P.M.B. 001, \\ Ipaja, Lagos, Nigeria. \\ ${ }^{3}$ Department of Pure and Applied Chemistry, Kebbi State University of Science and Technology, Aliero.
}

Received: 3/5/2019

Accepted: $15 / 3 / 2020$

\begin{abstract}
Flavonoid-metal complexes from the medicinal plant, Chromolaena Odorata were synthesized in this study using a standard method. Flavonoid extracts complexes, namely Mn-flavonoid complex, Co-flavonoid complex, Zn-flavonoid complex, and Cd-flavonoid complex were characterized using Fourier-Transform Infrared spectroscopy technique (FT-IR). Based on IR data, it was observed that the complexes shifted to lower frequencieswhen compared with the extract, indicating the interaction of the $\mathrm{C}=\mathrm{O}$ and $\mathrm{O}-\mathrm{H}$ groups during the complex formation. It was observed that the complexes were synthesized at a certain condition, which is acidic,with $\mathrm{pH}$ values ranging from 2.11 to 3.68 . The conductance values $\left(\Lambda_{\mathrm{m}}\right)$ of the complexes were found to be in the range of 7-15 $\Omega^{-1} \mathrm{~cm}^{2} \mathrm{~mol}^{-1}$, which indicates that the complexes are non-electrolytes. The synthesized flavonoid-metal complexes and the extract were assayed for antibacterial activity against several pathogenic bacteria (Escherichia coli, Klebsiella pneumonia, Staphylococcus aureus, Pseudomonas aeruginosa) and fungi (Aspergillus niger, Blastomyces dermatitidis, Candida albicans, Cryptococcus gattii) by measuring the zone of inhibition. The complexes were active and highly antibacterial to all organisms when compared with extract.
\end{abstract}

Keywords: Flavonoid, Metal Complexes, Extract, Microorganisms, Synthesis, Chromolaena Odorata.

\section{Introduction}

Flavonoids can be referred to as one group of the natural products which are present in plant parts, such as seeds, bark and flowers. Al-Obeidi et al. (2016)[1] reported that flavonoids can be extracted from the petals of plants. In addition, flavonoids exhibited different pharmacological effects such as antimicrobial and anti-oxidant ones [2]. The anti-oxidant activity of flavonoids depends on theirability to scavenge free radicals that may cause DNA damage [3]. Flavonoids have great beneficial effects on human health and more efforts are made to isolate their constituents [4]. They also support the cardiovascular and nervous systems along with detoxification of potentially tissue-damaging molecules $[5,6]$. They behave as chemical messengers and physiological regulators. They are polyphenolic compounds synthesized in the roots of the plants andfound in human diet such as fruit and vegetable which contain high levels of flavonoids [7]. The aim of this present research is to synthesize flavonoid metal complexes which will be more effective than their parent flavonoid extraction. 


\section{Methodology \\ Apparatus and Materials}

The leaves used for this research belong to Chromolaena Odorata which was collected in Ilorin, Kwara state Nigeria. The solvent (ethanol) and metal ions $\left(\mathrm{MnCl}_{2}, \mathrm{CoCl}_{2}, \mathrm{CdCl}_{2}\right.$, and $\mathrm{ZnCl}_{2}$ ) were used without any further purification. They were obtained from Sigma Aldrich Company, United States of America. The apparatus used were hotplate, conical flask and beakers.

\section{Preparation of the plant leaves}

Chromolaena Odorata (is a perennial plant with many stemmed shrub. It can be reproduce from the root part) used in this research was obtained from a house garden in Tanke, Ilorin, Kwara state, Nigeria. The plant leaves were freed from sand and dirt which might be present. They were washed thoroughly with clean tapwater followed by distilled water, then allowed to air dry for days. Later, they were grinded using mortar and pestle to obtain a fine powder. The pulverized sample was stored in a sample bottle and labeled for further analysis.

\section{Flavonoid extraction from plant leaves}

The extraction procedure described by Maitera et al. (2018) was adopted [8]. Ten grams of the dried leaves powder wasweighed and extracted using 75\% $(10 \mathrm{ml})$ ethanol for about 1 hour at a temperature of about $65{ }^{\circ} \mathrm{C}$. The aqueous extractwas then filtered into a conical flask and evaporated to dryness. The dried samples were weighed and marked.

\section{Synthesis of flavonoid-metal complexes}

The metal ions $\mathrm{MnCl}_{2}, \mathrm{CoCl}_{2}, \mathrm{CdCl}_{2}$, and $\mathrm{ZnCl}_{2}(0.20 \mathrm{~g} / \mathrm{mol}, 0.24 \mathrm{~g} / \mathrm{mol}, 0.18 \mathrm{~g} / \mathrm{mol}$ and $0.24 \mathrm{~g} / \mathrm{mol}$, respectively) were weighed in a desiccator and dissolved in distilled water. Solutions of the metals (15 $\mathrm{ml}$ ) were added slowly to the solution of the extracted flavonoid $(15 \mathrm{ml})$. The mixed solution was thoroughly stirred on hot plate for $45 \mathrm{~min}$ at $75{ }^{\circ} \mathrm{C}$. Formation of precipitates was observed and the $\mathrm{pH}$ was determined. The formed precipitates were filtered in a vacuum system, washed, and dried.

\section{Characterization}

The melting point of the plant extract-metal complexes were recorded on Gallenkamp melting point apparatus (Melting point SMP 10). Conductivity measurements were performed using Jenway 4510 conductivity meter at the Department of Chemistry, University of Ilorin, Ilorin, Nigeria. The FT-IR results were recorded in $\mathrm{KBr}$ pellets within the range of 400-4000 $\mathrm{cm}^{-1}$ on Buck Scientific M500 IR spectrometer at the Redeemer University, Sango-ota, Ogun state, Nigeria. The $\mathrm{pH}$ of the complexes was determined on Jenway model 3510 bentop pH meter. The isolated organisms: Escherichia Coli, Klebsiella Pneumonia, Staphylococcus aureus, Pseudomonas aeruginosa, Aspergillus niger, Blastomyces, Candida Albicans and Cryptococcus gattii were used for screening the antimicrobial activity of the complexes at the Department of Microbiology, University of Ilorin, Ilorin, Nigeria.

\section{Antimicrobial analysis}

Antimicrobial activities of the flavonoid extract and its complexes were measured according to Mohammed et al. (2014) [9] method. Seven grams of nutrient agar was weighed into a $250 \mathrm{ml}$ conical flask containing distilled water. It was thoroughly mixed and heated for about $15 \mathrm{~min}$. to ensure complete dissolution, and then sterilized for 24 hours in an autoclave at $121{ }^{\circ} \mathrm{C}$. The sterilized agar was transferred into sterilized petri dishes to solidify. A $1 \mathrm{~cm}^{3}$ hole was made in the plate. Solutions of the extract and its complexes were prepared by adding $5 \mathrm{~g}$ of the compounds to $1 \mathrm{~L}$ of ethanol at a concentration of $5 \mathrm{mg} / \mathrm{ml}$, which were poured into the hole in the petri dish and kept inthe incubator for a day. Zones of inhibition were then evaluated.

\section{Results and Discussion \\ The chemistry of the compounds}

The reaction products between the flavonoid and the transition metal (II) ions along withtheir physicochemical properties are presented in Table-1. It was observed that $\mathrm{ZnCl}_{2}$ complex has the highest $\mathrm{pH}$ value being formed at an acidic condition while, $\mathrm{CdCl}_{2}$ complex has the lowest $\mathrm{pH}$ value. The $\mathrm{MnCl}_{2}, \mathrm{CoCl}_{2}$ and $\mathrm{CdCl}_{2}$ complexes have $\mathrm{pH}$ values lower than 3.0 which may be due to the presence of flavonoids in their interactingform. All the formed complexes were colored and stable in air. The melting points of the complexes were higher than that of the extract (within $116-141^{\circ} \mathrm{C}$ ). In addition, $\mathrm{ZnCl}_{2}$ complexes showed the highest conductivity $\left(15 \Omega^{-1} \mathrm{~cm}^{2} \mathrm{~mol}^{-1}\right)$ that is possibly because of un-dissociated complexes in the solvent (DMSO). The complexes are non-electrolytic in nature. It wasreported in previous works that DMSO andDMF are among the solvents used for the determination of conductivity. The magnetic moment of the $\mathrm{Mn}(\mathrm{II}), \mathrm{Co}(\mathrm{II}), \mathrm{Cd}(\mathrm{II})$ and $\mathrm{Zn}$ (II) 
complexes are 3.42 B.M., 3.18 B.M., 3.76 B.M. and 3.15 B.M, respectively. The magnetic susceptibilities are independent of their field strength which are identified by their magnetism contribution.

Table 1-Physicochemical properties of the flavonoid extract and its complexes

\begin{tabular}{lclll}
\hline $\begin{array}{l}\text { Extract/ } \\
\text { Complexes }\end{array}$ & $\begin{array}{l}\text { Conductivity } \\
\mathbf{\Omega}^{-\mathbf{1}} \mathbf{c m}^{\mathbf{2}} \mathbf{m o l}^{\mathbf{- 1}}\end{array}$ & $\begin{array}{l}\text { Melting point } \\
(\mathbf{0} \mathbf{C})\end{array}$ & $\mathbf{p H}$ & $\boldsymbol{\mu}_{\text {eff }}(\mathbf{B . M})$ \\
\hline Mn-flavonoid complex & 7 & 141 & 2.96 & 3.42 \\
Co-flavonoid complex & 11 & 120 & 2.45 & 3.18 \\
Cd-flavonoid complex & 9 & 123 & 2.11 & 3.76 \\
Zn-flavonoid complex & 15 & 116 & 3.68 & 3.15 \\
\hline
\end{tabular}

Footnote: $\mu_{\text {eff }}=$ Magnetic momen

Infrared analysis

The infrared(IR) data of the extract and complexes are presented in Table- 2. It was observed that the IR spectrum of the extract indicates a frequency at $1694 \mathrm{~cm}^{-1}$ which is attributed to $\mathrm{C}=\mathrm{O}$. This frequency was shifted to a lower one,within the range $1633-1656 \mathrm{~cm}^{-1}$, in all the complexes. This indicates that an interaction occurs at the carbonyl group $v(\mathrm{C}=\mathrm{O})$ with the central metal ions. The $\mathrm{OH}$ group which is within $3533-3585 \mathrm{~cm}^{-1}$ showed the presence of hydroxyl group and water (Figure- 1). The presence of water/ moisture gave a broad band that appeared in the regions $3533-3585 \mathrm{~cm}^{-1}$; this can be due to $v(\mathrm{O}-\mathrm{H})$ stretching and $v(\mathrm{O}-\mathrm{H})$ rocking vibrations, respectively. This further supports the presence of non-ligands assignable to the rocking mode of water [10] and confirms the formation of the complexes [11].

Table 2-FTIR spectral data of the flavonoid and its metal complexes

\begin{tabular}{|c|c|c|c|c|c|c|}
\hline $\begin{array}{l}\text { Extract } \\
\text { O-H alcohol } \\
\text { /complexes }\end{array}$ & $\begin{array}{l}\mathrm{C}=\mathrm{O} \\
\left(\mathrm{cm}^{-1}\right)\end{array}$ & stretch $\left(\mathrm{cm}^{-1}\right)$ & C-H & $\begin{array}{l}\text { llkane } \\
\text { stretch }\left(\mathrm{cm}^{-1}\right)\end{array}$ & $\mathrm{C}-\mathrm{O}$ a & $\begin{array}{l}\text { cohol } \\
\text { stretch }\left(\mathrm{cm}^{-1}\right)\end{array}$ \\
\hline $\begin{array}{r}\text { Extract (Flavonoid) } \\
3510\end{array}$ & & 1694 & & 2911 & & 1019 \\
\hline $\begin{array}{l}\text { Mn-flavonoid complex } \\
3585\end{array}$ & 1656 & & 2938 & & 1066 & \\
\hline $\begin{array}{l}\text { Co-flavonoid complex } \\
3533\end{array}$ & 1649 & & 2946 & & 1058 & \\
\hline $\begin{array}{l}\text { Cd-flavonoid complex } \\
3558\end{array}$ & 1653 & & 2958 & & 1063 & \\
\hline $\begin{array}{c}\text { Zn-flavonoid complex } \\
3536\end{array}$ & & 1633 & & 2934 & & 1051 \\
\hline
\end{tabular}

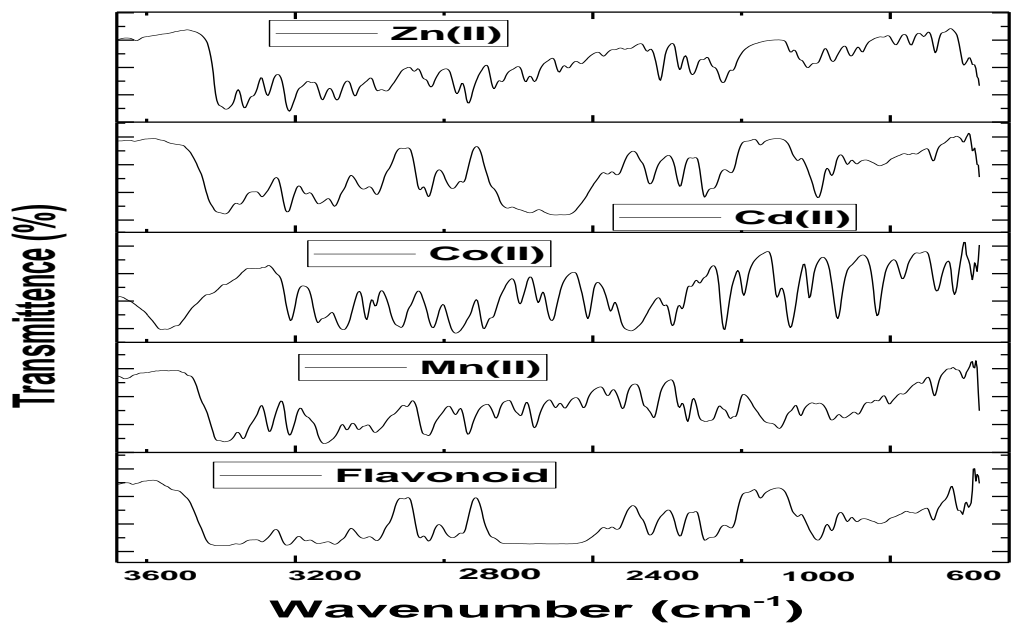

Figure 1-FT-IR spectra of the flavonoid and its metal complexes 


\section{Antimicrobial activities of the compounds}

The extract and its complexes were screened against some selected organisms, as presented in Tables-(3 and 4). It was observed that the flavonoid extract was not effective against Klebsiella pneumonia and Staphylococcus aureus. The complexes were active and highly antibacterial to all organisms when compared with extract. DMSO that acted as control did not show any effects on the organisms. The antifungal activitiesof the extract and its complexes are presented. The results indicate that the complexes were more harmful than their extract against the organisms at certain conditions. The complexes showed more antifungal activities, which can be as a result of the effects of the metal on normal cellular process such as DNA replication $[12,13]$. This may be due to the solubility of the extract in the solvents [14]. A previous work studied the antibacterial activity of flavonoids which havethe ability to form complexes [15]. It was observed that the complexes showed larger zones of inhibitory after interacting with the flavonoid extract.

Table 3-Antibacterial activities of the flavonoid extract and its complexes

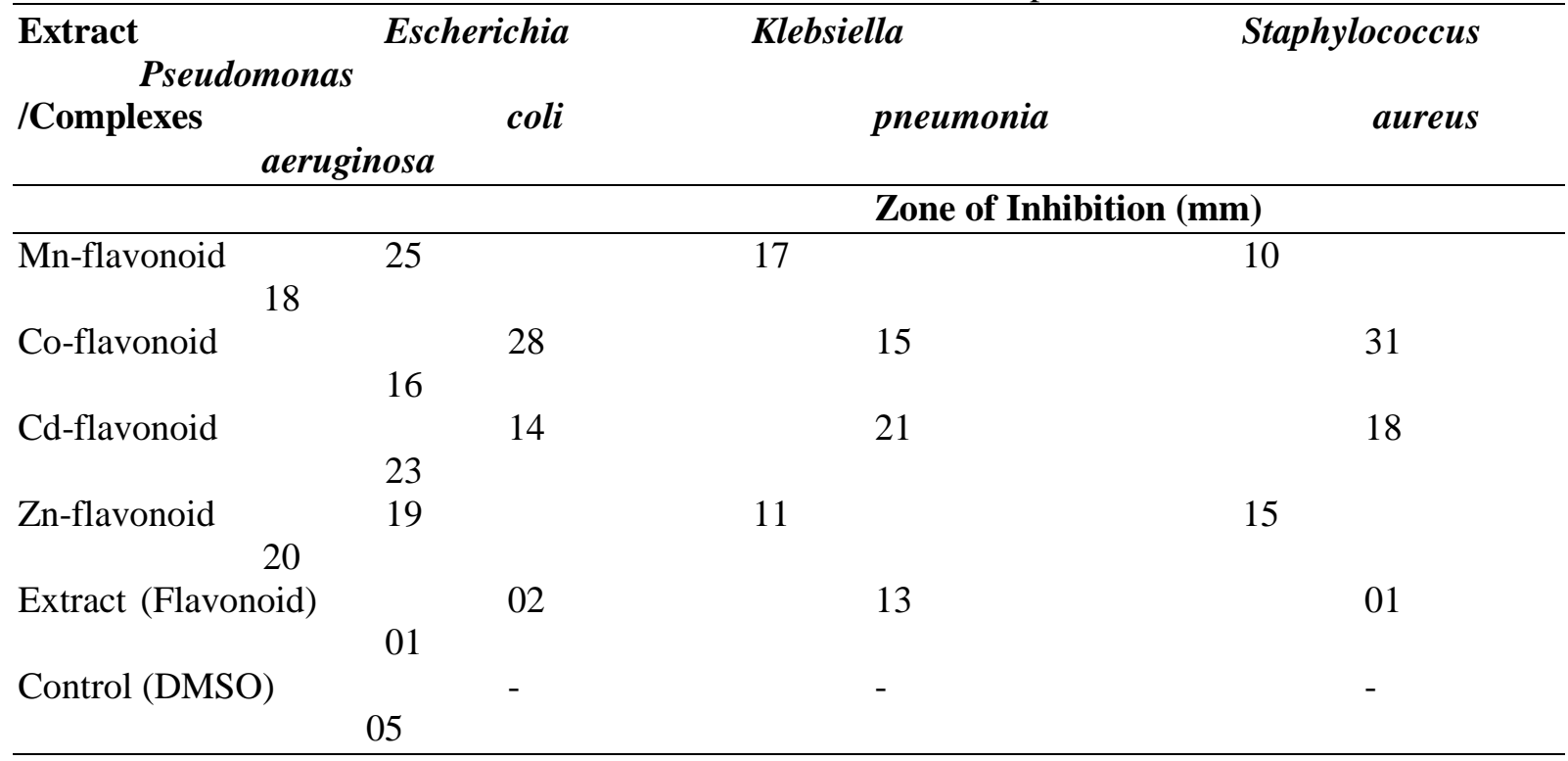

Table 4-Antifungal activities of the flavonoid extract and its complexes

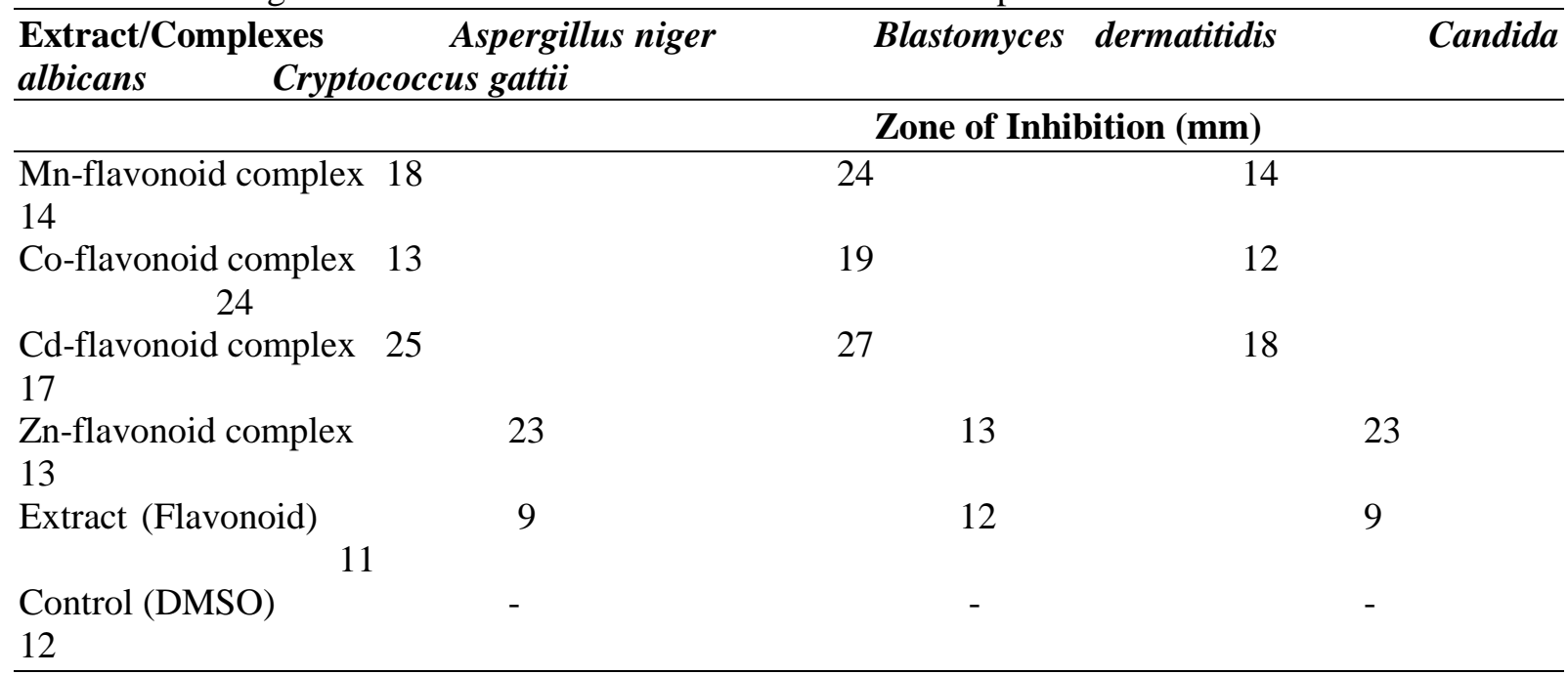

\section{Job's method of continual variation}

Job's method of continual variation was used to determine the stoichiometric ratio between the metals and the extract, as presented in Tabl- 5 [16]. Absorbance against mole fraction was plotted in each of the complexes (Figure-2). This indicated a curve with maximum absorbance as a result of 
ligand mole fractions and interactions at 1:1 metal -ligand ratio in all complexes [17]. The maximum values of $\mathrm{Mn}(\mathrm{II}), \mathrm{Co}(\mathrm{II}), \mathrm{Cd}(\mathrm{II})$ and $\mathrm{Zn}(\mathrm{II})$ on the Job's plot were $0.65,0.56,0.67$ and 0.45 respectively. It is observed that in order to get an estimate stoichiometry, the sum total of the flavonoid extract and its complexes must be related to the dissociation constant. The maximum number on the Job's plot corresponds to the stoichiometry of the extract and the complexes if there are high concentrations $[17,18]$. This helps to understand the equilibrium constant of the complexes.

Table 5-Results of Job's method of continuous variation for flavonoid-metal complexes

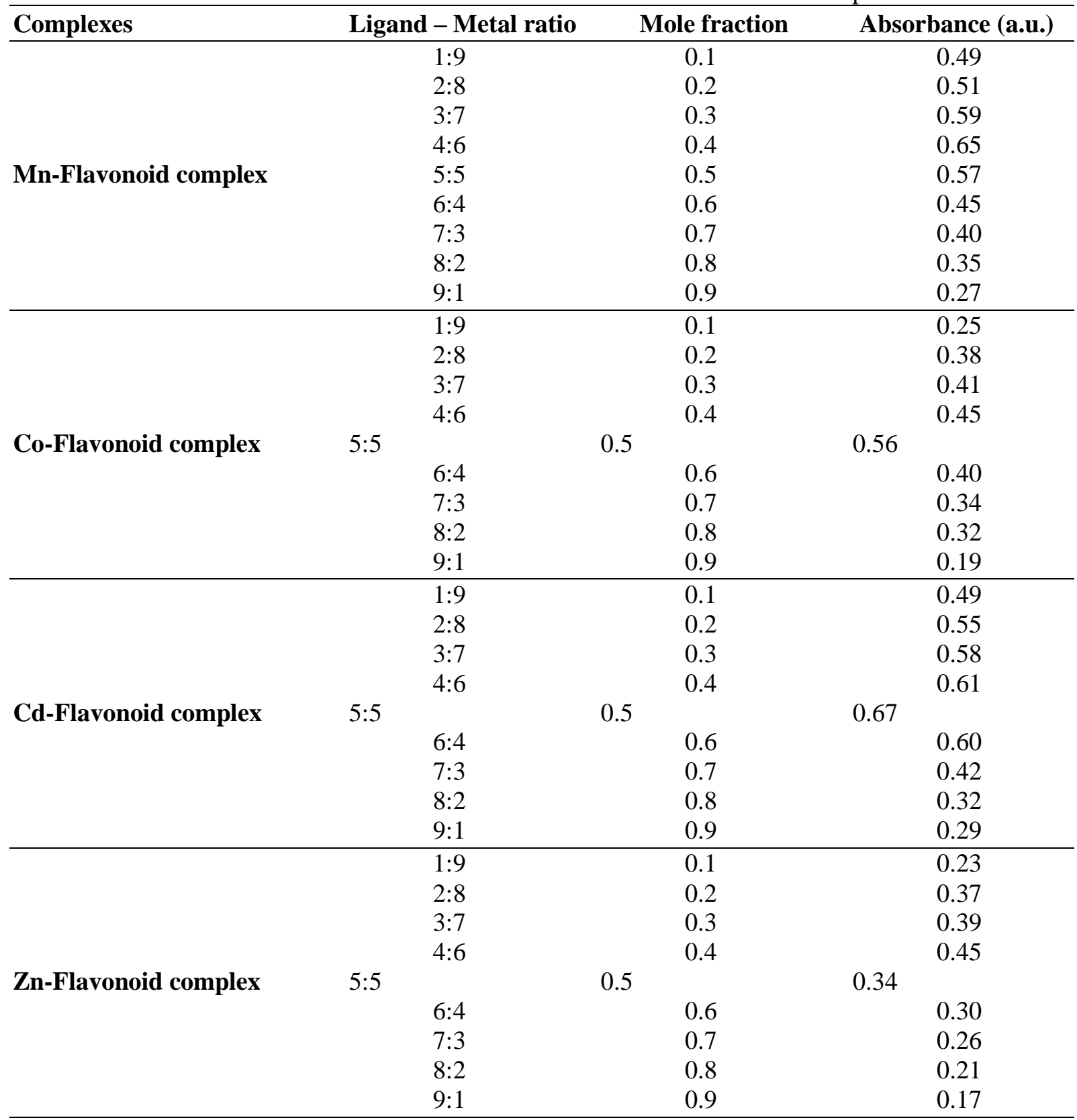




\section{Mn-Flavonoid complex}

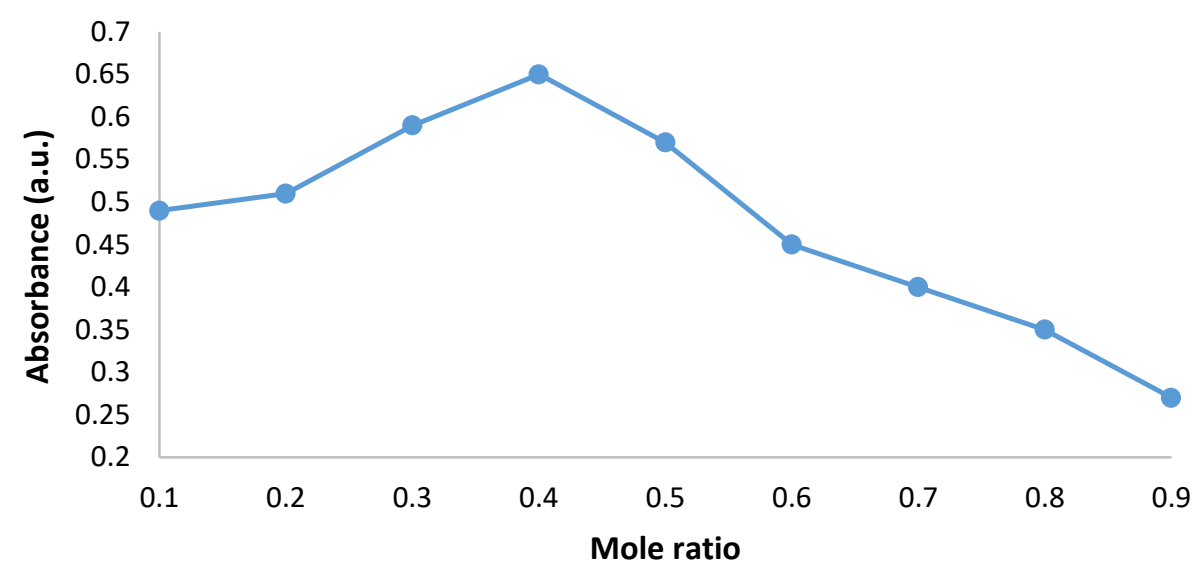

\section{Co-Flavonoid complex}

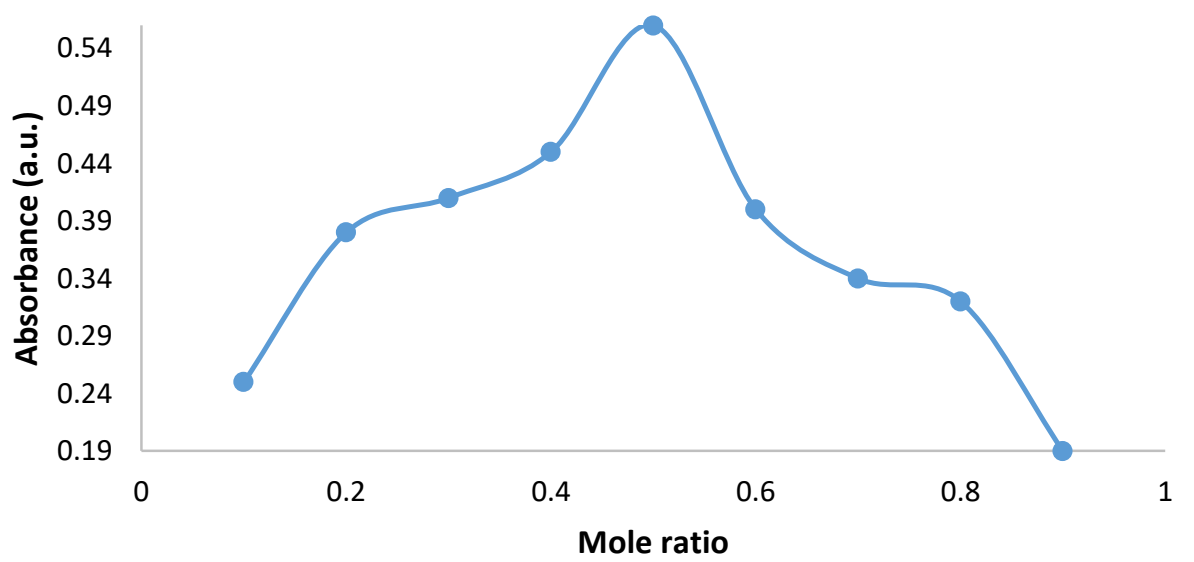

\section{Cd-Flavonoid complex}

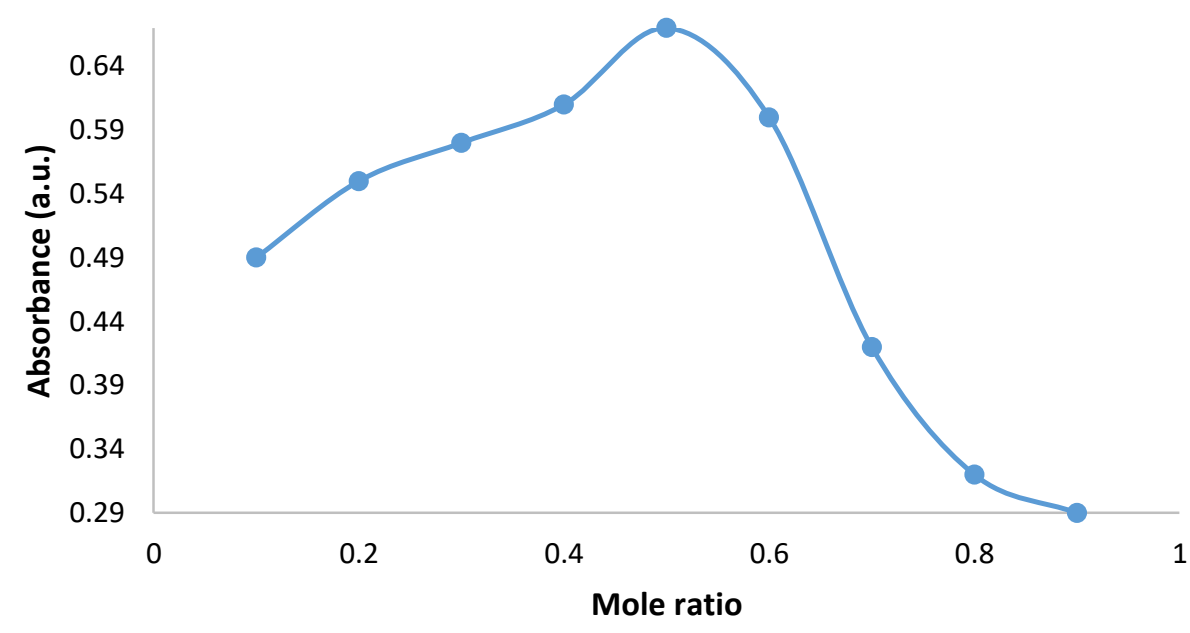




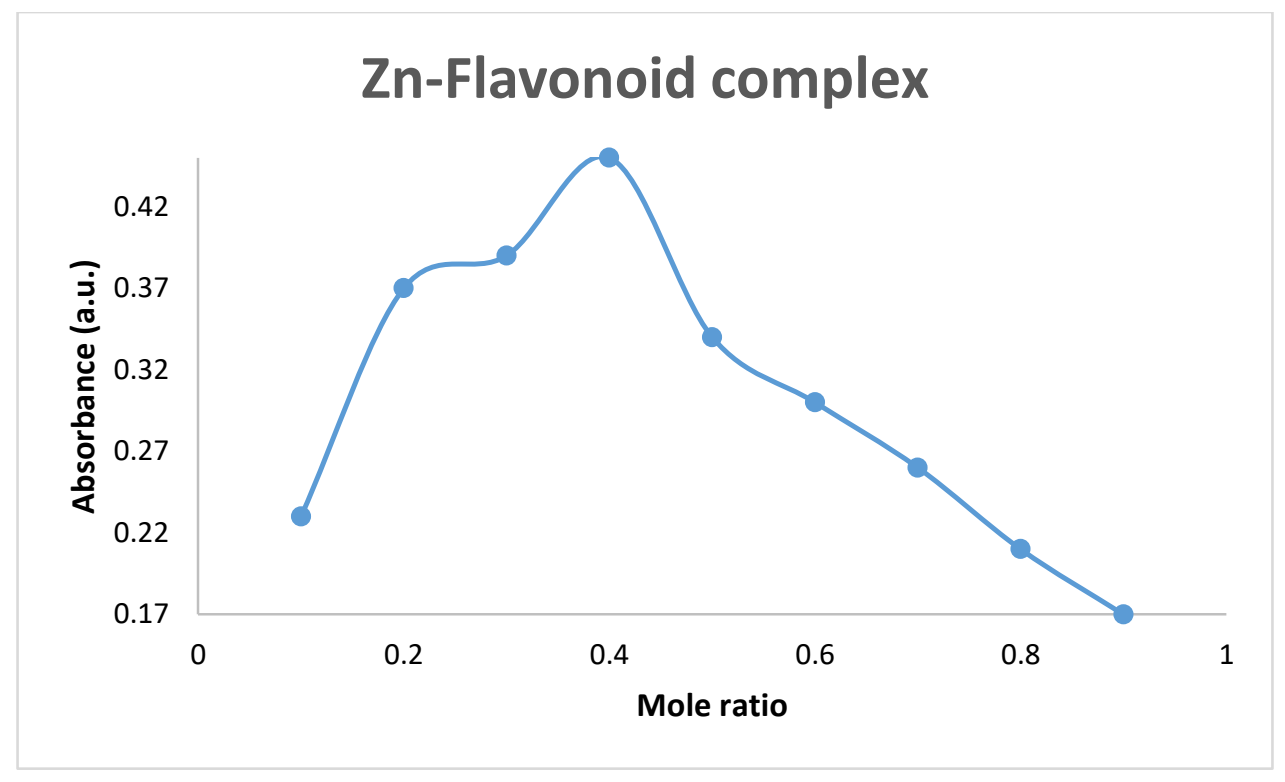

Figure 2-Curves showing the results of Job's method of continuous variation for flavonoid-metal complexes.

\section{Conclusions}

This study confirms the preparation of metal complexes using the flavonoid extracts from the medicinal plant Chromolaena odorata. The results confirmed the interactions between the metal ions and the flavonoid. The bands of $v(\mathrm{C}=\mathrm{O})$ and $v(\mathrm{O}-\mathrm{H})$ of the flavonoid were shifted to lower frequencies in all complexes. It was observed that the complexes were formed at an acidic condition of a $\mathrm{pH}$ value that is lower than 4. According to the results, the metal ions help to increase the activity of flavonoid complexes, as exemplified by the anti -microbiological study. Cd-complex was found to be the most effective among the other complexes against Blastomyces dermatitidis.

\section{Conflict of interest}

The authors have no conflict of interest to declare.

\section{References}

1. Al-Obaidi, O. M. 2016. Synthesis, characterization, theoretical and antimicrobial evaluation of new $\mathrm{Mn}(\mathrm{II}), \mathrm{Cu}$ (II) and $\mathrm{Zn}$ (II) complexes of flavylium salt. International Journal of Biochemistry, Biophysics \& Molecular Biology,1(1): 31-35

2. Bear, W. L. and Teel, R. W. 2000. Effect of citrus phytochemicals on liver and lung cytochrome P450 activity and on the in vitro metabolism of the tobacco specific nitrosamine NKP, Anticancer Research, 20: 3323-3329.

3. Jovanovic, S. V., Steenken, S., Tosic, M., Marjanovic, B. and Simic, M.G. 1994. Flavonoids as antioxidants. Journal American Chemical Society, 116: 4846-4851.

4. Hertog, M. G. L., Feskens, E. J., Hollman, P. C., Katan, M. B. and Kromhout, D. 1993. Dietary antioxidant flavonoids and risk of coronary heart disease: The Zutphen Elderly Study. Lancet, 342: 1007-1011.

5. Pereira, R. M. S., Andrades, N. E. D., Paulino, N.; Sawaya, A. C. H. F.; Eberlin, M. N.; Marcucci M. C.; Favero, G. M.; Novak, E. M.; Bydlowski, S. P. 2007. Synthesis and characterization of a metal complex containing naringin and $\mathrm{Cu}$, and its antioxidant, antimicrobial, anti-inflammatory and tumor cell cytotoxicity. Molecules, 12: 1352-1366.

6. Malesev, D. and Kuntic, V. 2007. Investigation of metal-flavonoid chelates and the determination of flavonoids via metal-flavonoid complexing reactions. Journal of the Serbian Chemical Society, 72: 921-939.

7. Bravo, A. and Anacona, J. R. 2001. Metal complexes of the flavonoid quercetin: Antibacterial properties. Transition Metal Chemistry, 26: 20-23. 
8. Maitera, O. N., Louis, H., Barminas, J. T., Akakuru, O. U. and Boro, G. 2018. Synthesis and characterization of some metal complexes using herbal flavonoids. Natural Products Chemistry Research, 6: 314.

9. Mohammed, A., Raja, S. A. and Mujafar, K. N. 2014. Antimicrobial applications of transition metal complexes of benzothiazole based terpolymer: synthesis, characterization, and effect on bacterial and fungal strains. Bioinorganic Chemistry and Applications, vol. 2014, Article ID: 764085 .

10. Ejidike, I. P. and Ajibade, P. A. 2016. Synthesis, characterization, anticancer, and antioxidant studies of $\mathrm{Ru}(\mathrm{III})$ complexes of monobasic tridentate Schiff bases. Bioinorganic Chemistry and Applications, vol. 2016, Article ID: 9672451.

11. Ejidike, I. P. and Ajibade, P. A. 2017. Synthesis, spectroscopic, antibacterial and free radical scavenging studies of $\mathrm{Cu}(\mathrm{II}), \mathrm{Ni}(\mathrm{II}), \mathrm{Zn}(\mathrm{II})$ and $\mathrm{Co}(\mathrm{II})$ complexes of 4,4'-\{ethane-1,2diylbis[nitrilo(1E)eth-1-yl-1-ylidene] dibenzene-1,3-diol Schiff base. Journal of . Pharmaceutical Science and Research, 9(5): 593-600.

12. Al-Hassani, R. A., Olfata N. and Mahmood, A. T. 2015. Synthesis, characterization, theoretical studies and biological activities of naringin metal complexes. Acta Chimica and Pharmaceutical Indica, 5(3): 129-142

13. Zhang, H., Wong, C. W., Coville, P. F. and Wanwimolruk, S. 2000. Effect of the grapefruit flavonoid naringin on pharmacokinetics of quinine in rats. Drug Metabolismdrug Interaction, 17: 351-363.

14. Holetz, F. B., Pessini, G. L., Sanches, N.R., Cortez, C. V. and Nakamura, B. P. D. 2000. Filho screening of some plants used in the Brazilian folk medicine for the treatment of infectious diseases. Memorias do Instituto Oswaldo Cruz, 97: 1027-1031.

15. Soniya, M., Anitha, T.K.S. and Sankareswari, P. 2013. In vitro antibacterial activity of plant extracts against Gram positive and Gram negative pathogenic bacteria. International Journal of Microbiology Immunology Research, 2: 001-005.

16. Mansour, F. and Danielson, N.2012. Ligand exchange spectrophotometric method for the determination of mole ratio in metal complexes. Microchem J, 103:74-78.

17. Kuljanin, J., Janković, I. and Nedeljković, J. 2002. Spectrophotometric determination of alendronate in pharmaceutical formulations via complex formation with Fe(III) ions. J Pharm Biomed Anal, 28:1215-1220.

18. Huang, C.Y. 1982.Determination of binding stoichiometry by the continuous variation method: The Job Plot. Methods in Enzymology, 87: 509-525. 